\title{
Research on the Relationship between Internet Finance and Domestic Consumption
}

\author{
$\mathrm{Hu}$ Yue \\ Shaanxi normal university \\ Xi'an, China \\ 1558534465@qq.com
}

\begin{abstract}
In recent years, third party internet payment which is the part of Internet finance has occupied financial markets rapidly due to its own advantages of convenient payment, convenient application and time saving. Internet finance has brought the challenge to traditional finance, and at the same time, it is changing the consumers' behavior. Based on the cointegration theory of econometrics, this paper conducts an empirical research on Internet finance and domestic consumption in China. The results show that the total domestic consumption and Internet finance have a significant positive long-term equilibrium relationship. In the long term, the expansion of Internet financial scale can become the Granger cause of the change of total domestic consumption through the co-integration relationship. Therefore, Internet finance promotes the growth of domestic consumption.
\end{abstract}

Keywords-Internet finance; Co-integration theory; Domestic consumption; Granger

\section{INTRODUCTION}

Consumption is the starting point and destination of social reproduction. Compared with investment and export, it has incomparable advantages in promoting economic growth. In recent years, under the new normal of the economy, consumption has become the main driver of China's economic growth. At the same time, the development momentum of Internet finance has been advancing rapidly. With the help of Internet and mobile communication technology, the functions of financing, payment and information intermediary are realized. At present, its main development modes include third-party payment, P2P lending and crowd funding. The emergence of Internet finance largely makes up for the deficiency of traditional finance. While bringing great convenience to people's life, it is also influencing people's consumption patterns, consumption habits and consumption psychology. Is there a co-integration relationship between the growth of domestic consumption and Internet finance? Can the development of inclusive finance like Internet finance promote the growth of domestic consumption? Based on the co-integration theory, this paper made an empirical study on Internet finance and domestic consumption in China.

\section{LITERATURE REVIEW}

As a hot topic, Internet finance has attracted wide attention from all walks of life. Correspondingly, there have been a lot of literature on Internet finance. In foreign countries, the research on Internet finance related issues mainly focused on the research on the innovative model of Internet finance. Tarazi and Breloff (2010) compared the traditional banking model with the mobile finance model. They found that mobile finance has unparalleled advantages over traditional finance. Freedman and Jin (2011) made a comparative analysis of the traditional lending relationship and $\mathrm{P} 2 \mathrm{P}$ network lending, one of the main modes of Internet finance. In addition to P2P lending analysis, Agrawal et al. (2013) analyzed the operation mechanism of crowd funding and also analyzed the development trend of crowd funding model. Chen (2012) studied that mobile payment, an Internet financial model, can reduce the transparency of payment. Shoppers do not need to take practical action, such as handing over money. Because the payments can be finished by the Square wallet. This makes it easier for consumers to increase their spending without a strong sense of sacrifice for cash.

Domestic research mainly focused on the following aspects: Research on the relationship between Internet finance and traditional finance, analysis on the operation mode of Internet finance, discussion on the macro-economic influence of Internet finance and the risk control and system construction of Internet finance. Li Yulin (2009) believed that the guarantee provided by third-party payment to online transactions has greatly promoted the development of online shopping, but brought impact and challenge to the traditional bank payment system. Xie ping and Zou Chuanwei (2012) studied Internet finance earlier. They pointed out that Internet finance, with the help of Internet and mobile communication technology, has realized the functions of financing, payment and information intermediary. Liao $\operatorname{Li}(2014)$ pointed out that as a classic of Internet financial mode, P2P lending platform with the development of financial innovation around the world have been pouring into China, and caused a stir in the Chinese financial market. Yao Jie (2014) discussed the security problems of third-party payment from the aspects of Internet technology, finance, capital and law and put forward countermeasures to improve the security of payment. From the perspective of path dependence and government intervention, Yao Yaojun and Shi Danyan (2017) revealed the formation 
logic of regional differentiation development of Internet finance. In addition, they suggested that government intervention can boost the development of Internet finance in these areas. From the existing literature, there are few studies on the relationship between Internet finance and domestic consumption. Whether the development of Internet finance, such as inclusive finance, can promote the growth of domestic consumption? It is of great significance to study this problem to expand domestic demand and promote the healthy operation of national economy.

\section{THEORETICAL ANALYSIS}

The impact of Internet finance on domestic consumption mainly comes from the following aspects: Internet finance improves the income effect of residents, Internet finance promotes the conversion effect of household consumption. Internet finance facilitates transactions and stimulates the desire of residents to consume more things.

\section{A. Internet finance improves the income effect of residents}

Modigliani proposed the consumption theory of "life cycle hypothesis" in 1954. This theory suggested that every consumer will make a reasonable allocation of income in their own consumption expenditure, so as to maximize the efficiency of capital use. Therefore, consumers will make the best choice between current consumption and future consumption. The future expected income of residents is affected to some extent by the interest rate of financial assets. In turn, the interest rate on financial assets will have an impact on consumers' current consumption. Since 2013, Alibaba launched $\mathrm{yu}$ 'ebao and tencent launched tenpay online payment platform. These two payment platform launched more than $6 \%$ annual interest rate of financial products for users. The financial products' annual interest rate is much higher than that of traditional commercial banks. Therefore, most people transfer money from commercial banks to online financial platforms represented by yu'ebao and tenpay. With the enrichment and development of Internet financial products, the investment channels of consumers have also been widened. As a result, consumer savings rates have been raised and the income effect of residents has been increased.

\section{B. Internet finance promotes the conversion effect of residents' consumption}

Take yu 'ebao for example, consumers deposit their money in yu 'ebao, where they can not only get income, but also withdraw and pay at any time. However, traditional financial institutions have great constraints on saving, investment and consumption. Therefore, the innovation of Internet financial products have greatly eased the transformation constraint. At a given income level, consumers can either invest their savings or convert the benefits of saving and investment into spending. This makes it much easier for consumers to save and invest, which can improve their consumption tendency to some extent.

\section{Internet finance stimulates the desire of residents to consume}

One of the major modes of Internet finance is third-party payment. There is a big difference between the consumer's psychological experience of paying through the third-party payment platform and that of paying by cash. From the point of view of psychological account, the psychological account loss caused by the third-party payment platform is often far weaker than the actual account loss caused by cash payment. Therefore, the Internet finance changed people's consumption psychology and consumption habit. It makes consumers more rapid in making consumption decisions, more active in consumption behaviors, and more prone to impulse consumption. In short, Internet finance facilitates people's transaction mode, changes people's consumption habits, and stimulates people's desire to consume.

\section{EMPIRICAL RESEARCH}

\section{A. Sample data}

This paper used the co-integration and error correction model to test the long-term equilibrium and short-term fluctuation relationship between the development of Internet finance and domestic consumption. The measurement software is Eviews8.0. The sample data involved are total consumption and Internet finance, from the national bureau of statistics and the wind database. Among them, the total amount of consumption, this paper selected the total amount of social consumer goods retail as the proxy variable of the total amount of consumption. The quarterly figures were calculated from the monthly data of the original total retail sales of social consumer goods. Internet finance, this paper selected the scale of Internet payment transactions in thirdparty payment as the proxy indicator for the development of Internet finance. CONS and INFI represented total consumption and Internet finance in units of 100 million yuan. The sample data were from the first quarter of 2007 to the third quarter of 2017. By looking at the timing diagram of CONS and INFI, CONS has strong seasonal fluctuations. INFI is not affected by seasonal factors. In order to eliminate the seasonal effects of CONS, this paper used the $\mathrm{x}-12$ method to make seasonal adjustments to the CONS data. The processed data is represented by CONS_SA. As can be seen from figure 1, China's total domestic consumption and Internet finance have similar trends of change, indicating that there may be a long-term equilibrium relationship between them.

\section{B. Stability test}

The premise of co-integration test is to test the stability of variables. As can be seen from the change trend in figure 1, the time series CONS_SA and INFI both have the same upward trend. That is, the two sequences are non-stationary. The ADF method is used for testing, and the test results are shown in table I.

It can be seen from table Ithat the original sequence of the two variables are not stable at the significance level of 5\%, but the first-order difference sequence is stable at the significance level of $5 \%$. Therefore, both variables are first-order single integer sequences, i. e. I(1). 


\section{Co-integration test}

Since both CONS_SA and INFI are first-order single integer sequences, there may be a long-term equilibrium relationship between the two variables, so OLS can be used to perform co-integration regression on the two variables. Through Granger causality test, it was found that there was a one-way causal relationship between CONS_SA and INFI, so CONS_SA was taken as the dependent variable for cointegration regression. The long-term equilibrium relationship model between two sequences was set as:

CONS_SA $=\alpha 0+\alpha 1 \mathrm{INFI}_{\mathrm{t}}+\mu \mathrm{t}$

The OLS estimation results of the co-integration equation are:

$$
\begin{aligned}
\text { CONS_SA } & =36379+0.9446 \mathrm{INFI}_{\mathrm{t}} \\
(14.17) \quad(20.22) &
\end{aligned}
$$

The R2 of model (2) was 0.830380 , and the D.W statistic was 0.043013 . The Lagrange multiplier test of the residual series of the model shows that the residual series of the model has serious sequence correlation. In order to eliminate the selfcorrelation of the model, the $\mathrm{AR}(1)$ term is added into the equation. The final long-term equilibrium relationship model is:

$$
\begin{array}{r}
\text { CONS_SA }=170596.5+0.2362 \mathrm{INFI}_{\mathrm{t}}+0.9896 \mathrm{CONS} \_\mathrm{SA}_{\mathrm{t}-1} \text { (3) } \\
(1.150)(2.88)(86.22)
\end{array}
$$

The R2 of the final model (3) was 0.998730, and the D.W statistic was 2.044177 .

LM test results indicated that the residual sequence of the model did not have sequence correlation, so the long-term equilibrium model may be set correctly. Then, ADF test was carried out for the residual sequence et calculated in equation (3). The appropriate test form was $(0,0,0)$, and the ADF test value was -6.62 . The critical value of $1 \%$ significance level was -4.20 , indicated that there was no unit root of et and it was a stable sequence. This indicated that CONS_SA and INFI $(1,1)$ are co-integrated. This shows that in the long run, the total domestic consumption and the development of Internet finance have established a significant positive long-term equilibrium relationship, and the marginal response of the total consumption to Internet finance is 0.23621 .

\section{Error correction model}

There is a positive long-term equilibrium relationship between the development of Internet finance and the total domestic consumption. In order to investigate the short-term fluctuation relationship between variables, an error correction model was established. The specific method was to take the stationary residual sequence et obtained in the co-integration regression result (3) as the error correction term, and to establish the corresponding first-order difference error correction model with CONS_SA as the dependent variable.

$$
\triangle \mathrm{CONS} \_\mathrm{SA}_{\mathrm{t}}=\beta_{1} \triangle \mathrm{INFI}_{\mathrm{t}}-\lambda \mathrm{ecm}_{\mathrm{t}-1}+\varepsilon_{\mathrm{t}}
$$

OLS estimation results of the error correction model (4) are as follows:

\section{$\triangle \mathrm{CONS} \_\mathrm{SA}_{\mathrm{t}}=0.1297 \triangle \mathrm{INFI}_{\mathrm{t}}+0.8069 \triangle \mathrm{CONS} \_\mathrm{SA}_{\mathrm{t}^{-}}$ $0.8703 \mathrm{ecm}_{\mathrm{t}-1}+\varepsilon_{\mathrm{t}}$}

$$
\begin{array}{lll}
(1.785) \quad(6.757) \quad(-3.821)
\end{array}
$$

All the explanatory variables of the error correction model passed the significance test. In order to further verify whether the model is set correctly, white noise test is needed for residual error correction model. Results were shown in table 4. The table shown that error correction model of residual error sequence of $\mathrm{ADF}$ test statistic was less than the critical value under the $1 \%$ significant level. And the significant probability was 0.000 , it showed that residual sequence was white noise characteristics. So the model set was correct. The results of the error correction model showed that the development of Internet finance had a positive impact on the total domestic consumption. At the same time, the error correction coefficient in the error correction model was 0.8703 , which was in line with the reverse correction effect. At the same time, it could reflect the strong adjustment of long-term equilibrium relationship to short-term fluctuation.

\section{E. Figures and Tables}

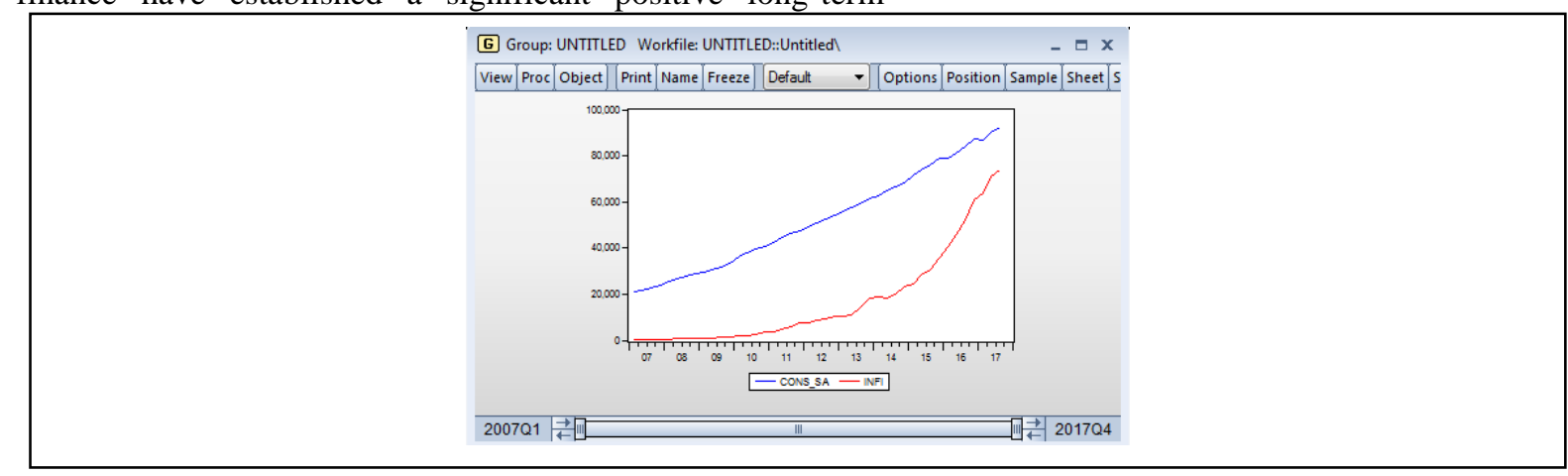

Fig. 1 Cons_sa and infi in a group graph 
TABLE I. SEQUENCE STABILITY TEST

\begin{tabular}{|c|c|c|c|c|c|}
\hline Variable & Model Type & $\begin{array}{c}\text { Augmented Dickey- } \\
\text { Fuller test statistic }\end{array}$ & Prob. & 5\% Threshold & Conclusion \\
\hline CONS_SA & $(\mathrm{C}, \mathrm{T}, 1)$ & -1.53 & 0.80 & -3.52 & not stable \\
\hline & $(\mathrm{C}, 0,1)$ & 3.37 & 1.00 & -2.93 & not stable \\
\hline & $(0,0,0)$ & 13.19 & 1.00 & -1.95 & not stable \\
\hline INFI & $(\mathrm{C}, \mathrm{T}, 9)$ & 2.49 & 1.00 & -2.56 & not stable \\
\hline & $(\mathrm{C}, 0,9)$ & 3.51 & 1.00 & -2.95 & not stable \\
\hline & $(0,0,0)$ & 11.56 & 1.00 & -1.95 & not stable \\
\hline CONS_SA & $(\mathrm{C}, \mathrm{T}, 0)$ & -9.02 & 0.00 & -3.52 & stable \\
\hline$\triangle$ INFI & $(\mathrm{C}, \mathrm{T}, 0)$ & -4.94 & 0.00 & -3.52 & stable \\
\hline
\end{tabular}

TABLE II. GRANGER CAUSALITY TEST BETWEEN SEQUENCES

\begin{tabular}{|c|c|c|c|}
\hline Null Hypothesis & Obs & F-Statistic & Prob. \\
\hline $\begin{array}{c}\text { INFI does not Granger Cause } \\
\text { CONS_SA }\end{array}$ & 41 & 2.85095 & 0.0079 \\
\hline $\begin{array}{c}\text { CONS_SA does not Granger Cause } \\
\text { INFI }\end{array}$ & & & 0.1802 \\
\hline
\end{tabular}

TABLE III. STABILITY TEST OF RESIDUAL ERROR SEQUENCE

\begin{tabular}{|l|l|l|}
\hline & t-Statistic & Prob.* \\
\hline Augmented Dickey-Fuller test statistic & -6.622665 & 0.0000 \\
\hline Test critical values: & -4.198503 & \\
\hline & -3.523623 & \\
\hline & -3.192902 & \\
\hline
\end{tabular}

TABLE IV. WHITE NOISE TEST

\begin{tabular}{|c|l|l|}
\hline & t-Statistic & Prob.* $^{*}$ \\
\hline Augmented Dickey-Fuller test statistic & -6.678658 & 0.0000 \\
\hline Test critical values: & -4.205004 & \\
\hline & -3.526609 & \\
\hline & -3.194611 & \\
\hline
\end{tabular}

\section{CONCLUSION AND ENLIGHTENMENT}

The theoretical analysis of this paper showed that internet finance improves the income effect of residents. And the internet finance promotes the conversion effect of residents' consumption. In addition, internet finance stimulats people's desire to consume, helps to improve their propensity to consume and thus promotes domestic consumption. This paper used the quarterly data of total social consumer goods from the first quarter of 2007 to the third quarter of 2017 as well as the third-party online payment scale in the Internet financial model. Based on the above data, the co-integration analysis of domestic consumption and Internet finance is carried out. The results showed that there has been a significant positive longterm equilibrium between the total domestic consumption and Internet finance. In the long run, the fluctuation of Internet finance can become the Granger cause of the change of domestic total consumption through the co-integration relationship. It can be seen that accelerating the development of Internet finance can indeed increase consumer spending. As one of the three carriages driving a country's economic growth, the growth of consumption will promote China's economic development. The enlightenment of the empirical results to the author is that the supervision of Internet finance should be further strengthened. To prevent the buyer's funds from being misappropriated and defrauded in the transaction process, and to create a safe and fast online consumption environment for consumers.

In order to promote the development of China's Internet finance and the further improvement of consumers' consumption capacity, the following Suggestions are proposed

(1)From the perspective of national macro-policy. The government should attach great importance to the development of Internet finance and give full play to the positive influence of Internet finance on consumption. We will vigorously develop the consumer economy, promote the concept of consumer finance and guide residents to invest in the Internet. In addition, there are still some irregularities in the development of Internet finance. The government should strengthen supervision and implement supervision policies to ensure the stability and security of transactions. 
(2) From the perspective of Internet finance development. Third-party payment platforms can seize opportunities to expand the scope of application of online payment. At the same time, it can actively develop online and offline consumption patterns. For example, online shopping and online ordering can work closely with the express industry. Internet finance should keep innovate and explore new ways to save time and reduce costs.

(3) From the perspective of residents themselves. Residents are the subject of social consumption. As consumers themselves, we should pay attention to the development of The Times, comply with the development trend of The Times, and actively integrate into social development. In the daily payment, residents can use online and offline diversified investment methods according to their own assets and risk preference to maximize their utility.

\section{REFERENCES}

[1] Tarazi M. and P. Breloff. Nonbank, "e- money issuers: regulatory approaches to protecting customer funds",CGAP Focus Note,2010.

[2] Freedman S.and G.Z.Jin, "Learning by doing with asymmetric information: evidence from prosper.com", NBER Working Paper No.16855,Issued in March, 2011.

[3] Chen, B. X, "The campaign to digitize your wallet is intensifying". The New YorkTimes, Sept, 2012.

[4] Agrawal A.,C. Catalini and A.Goldfarb, "goldfarb catalinimics of crowdfunding", NBER Working Paper, 2013.

[5] Li yu lin. "Economic analysis on the mechanism of third-party payment".[J] Journal of Business Economics. 2009. (In Chinese)

[6] Xie ping, Zou chuanwei, "Research on Internet financial model" [J]. Journal of Financial Research, 2012. (In Chinese)

[7] Yao jie, "Research on the security of third-party payment in e-commerce and its countermeasures", [J] Journal of Finance and Economics,2014. (In Chinese)

[8] Liao li, "It is the biggest challenge of financial supervision that Internet finance should regulate P2P and crowdfunding according to the business model "[J] China Economic Weekly,2014. (In Chinese) 